\title{
ECONOMIC EVALUATION OF DELAYS REDUCTION: A GLOBAL APPROACH
}

\author{
Agnès Dumolard ${ }^{1}$, Michel Pouly ${ }^{1}$, Rémy Glardon ${ }^{1}$ \\ ${ }^{1}$ Laboratory for Production Management and Processes \\ Department of Mechanical Engineering \\ Swiss Federal Institute of Technology, Lausanne \\ CH-1015 Lausanne, Switzerland \\ E-mail: agnes.dumolard@epfl.ch
}

\begin{abstract}
'Time-to-customer' and delays reductions are one of the main preoccupations in nowadays manufacture restructuring. Nevertheless, it is not precisely known when, and in what proportion, delays reduction is economically accurate. This paper aims to create a new global framework to support firm's decisions in order to quantify time in processes. The measurement of delays requires the co-ordination of production and market analysis. The marketing side is modelled with expert system methods, combining fuzzy logic, fuzzy neural networks and wavelet estimators. A new marketing-mix parameter, namely precision, is included in market modelling in order to represent the impact of delays. These efficient methods allow an accurate forecast of demand and duedates. The production side is characterised with discrete event simulation to capture the global complexity of production cases. Finally, market requirements and production features are compared to estimate profit losses due to poor production performances.
\end{abstract}

\section{INTRODUCTION}

'Time-to-customer' or namely the time required to fulfil a customer order, has become one of the main priorities in today's competitive world, including notions of costs, product quality and price. Manufacturing remains one of the key processes for a firm to survive. Delays represent a strategic weapon as well as the other marketing-mix parameters. 'Time-to-customer' has different values and implications, depending on the particular market segment and product positioning considered. Production systems need to react quickly to market changes. The introduction of flexibility, based on human, organisational or physical processes, has many implications on manufacture control and has a possible impact on the cost structure. Measuring the economic consequences of an investment in flexible devices is becoming a critical issue. The return on investment should include shortened delays as a positive fact to balance increased costs and potential positive influence on demand. It is therefore necessary to quantify the impact of time, for which only a global approach, including manufacturing and market conditions, can provide significant results. This paper intends to propose a global framework to 
quantify the implication of time reduction actions on profits. An econometric approach will be employed to evaluate delays in production and their effects on markets. Microeconomic theory supposes the optimisation of a firm profit:

$$
\text { Profit }=\text { Price * quantity sold }- \text { Costs for a given period } \Delta T
$$

This definition can be mathematically expressed as:

$$
\operatorname{Max} \Pi(\mathrm{t})=\sum \mathrm{P}(\mathrm{t}) * \mathrm{Q}(\mathrm{t})-\sum \operatorname{Costs}(\mathrm{t})
$$

Equation (1) introduces the links between markets and production in a continuous way. It can be easily approximated on a discrete period $\Delta \mathrm{T}$. Basically, two factors influence profit variations: $P \times Q$ and the sum of all costs. The first term comes from the market reaction to manufacture performances, while the second one represents production features in response to market demand. The marketing effects lean on the first term of the equation: prices and quantities sold are correlated with the strategic position of marketing mix variables, which themselves depend on production control. Any modifications of the market or manufacture environment involve a profit variation. Weak achievements in terms of delivery dates or frequent tardiness may in a long term affect the level of demand, even if the short horizon profit is not decreasing and the market growth potential is high. This latter statement stresses the need for a tardiness penalty to forecast profit decrease in a long-term horizon.

In a first part, a brief literature review will examine to what extent delays are included in production and market modelling. The second part will be dealing with the global problem modelling, divided into two parts: a market characterisation and a study of the manufacturing features. The major improvement provided by modelling techniques will subsequently be explained.

\section{TIME IMPLICATIONS: A BRIEF LITERATURE REVIEW}

This section briefly summarises the state of the art of delay implication in production and market modelling. All cited papers include delays as either a decision variable or an output result. The conducted literature review has revealed two main domains where lead-times have a critical impact: production control and market behaviour. This section is divided into three parts. The first one intends to examine delays and time evolutions in production modelling, combined with a statistical distribution of demand. The second one explores the market environment and the third one then encloses a demand modelling related to marketing-mix parameters into previous cited domains. The quantification of lead-times in production control has been widely expressed in MTO (Make-to-order) or MTS (Make-to-stock) problems. More generally, different types of approaches try to capture production systems behaviour: queuing theory (analytical modelling), heuristic approach and discrete event simulation. Analytical modelling has been widely addressed in multiple papers. Kim and Tang (1997) have examined and modelled manufacturing lead-time as a queuing model of a pull-based production control system for a single stage facility, in order to guarantee delivery date reliability. De et al. (1995) have proposed a general model to analyse time cost trade off and highlighted the need for a global approach. Corbey (1991) has studied the economic consequences of manufacturing speed by introducing mathematical 
functions depending on, among others, time for each production step. Discrete event simulation or queuing theory requires demand trend as input. Several papers intend to include demand trends within inventory policies or lot-sizing problems (Hariga , 1994, Rosling, 1989, Li and Qiu, 1996, Vendemia, 1995, Qiu and Loulou, 1995, Madu, 1990). Demand is stochastic, mainly based on Poisson processes, while classical inventory or queuing models such as $\mathrm{M} / \mathrm{M} / 1$ are added. Karmarkar et al. $(1985,1992)$ have shown that in presence of stochastic order arrivals, higher levels of capacity utilisation cause increased congestion and longer lead-times in a jobshop environment. Banker et al. (1988) have extended the Karmarkar model to include the effects of variability in processing and set-up times. Although these methods are valid in particular cases, queuing model theory fails in representing an entire production system in a dynamic way, as unfortunately, parameters evolution are stochastic and existing analytical models are not able to capture the global complexity of a real production case. To overcome this major drawback, discrete event simulation provides a powerful tool to dynamically model production on a large-scale. Spedding and Sun (1999), Selladurai et al (1996), Senechal and Tahon (1997) have simulated production features as a whole in different cases. As for demand setting, it seems quite difficult to adjust a statistical time-distribution without links to the underlined structure. This latter statement has emphasised the necessity to study market modelling. Marketing and micro-economic research has provided several models. Eliasberg, Lilien and Gatignon (1993) have compiled existing representations. Malhotra (1999) has provided a more applied research based on statistical methods validated with real cases. Basically, they integrate classical marketing-mix parameters to extract demand trends. However, due-dates are not included and the setting of all factors (such as quality) appears quite difficult. The exploration of demand modelling based on deterministic or pure statistical analysis does not succeed in building reliable models. A small number of parameters taken into account or the lack of links with market structure penalise the accuracy of results. As discussed above, delays in production are fixed by market requirements. The combination of marketing and production allows the realisation of the classical micro-economic basic principle, i.e. the so-called profit maximisation. Heliashberg and Steinberg (1993) have pointed out the absolute necessity of a combined (market and production) modelling and optimisation. The aggregation of these two domains has lead to a promising research area, namely the 'joint marketing-production problem'. Markets and manufacturing are simultaneously and analytically addressed to optimise profit. Several papers have considered delivery delay costs, which let demand to be sensitive to lead-time performances. Dewan and Mendelson (1990) have studied the optimal capacity and pricing decisions in a service facility setting where users have delay costs. Loch (1991) has treated demand as a function of full price, which is the price charged plus the cost of waiting. Li and Lee (1994) and Lederer and $\mathrm{Li}$ (1994) have proposed similar models to consider delivery delay costs. Recent papers have expressed demand as a function of price and a timerelated variable. For instance, So and Young (1994) have considered demand as a function of price and announced lead-time, while Hill and Khosla (1992) have assumed that price and actual lead-time are the variables that determine demand. In more recent years, several studies have recognised and examined the congestion costs caused by stochasticity in order arrivals as well as production and environments. Buss et al. (1994) have considered the joint marketing-production 
decision of simultaneously determining the optimal levels of mean demand volume and production capacity in a facility design setting. While these papers consider congestion costs, none of them model the impact of lead-times on demand. Palaka, Erlebacher, Kropp (1997) have developed a model that captures the full profit impact of stochasticity in demand arrivals as well as the production process when customers are delay-sensitive and a company incurs congestion costs and lateness penalties. Demand is simply set as a linear and stationary combination of price and lead-time. Hatoum and Chang (1997) have included the same demand expression to indicate inventory holding rate and cost importance on profit. Abab (1989) or Kingsman et al. (1993) consider quite the same characterisations, while decision variables and goals are different: either market effects on production or the opposite. Kim and Lee (1998) have developed a decision support system to co-ordinate marketing and production in a non-stationary problem. Demand is price-based while production is set as an economic order quantity (EOQ) problem for a short-term view. Alpern (1989) has considered a timely dependent demand based on pricequantity combinations as a decision variable to determine their effects on production capacity setting. These articles use analytical modelling such as simple queuing models and semi-linear market characterisation. Too few parameters are involved and semi-linear modelling without subjective judgements cannot precisely model delays along the supply-chain. Necessary new techniques have to overcome these defects. In summary, major drawbacks have been identified so that further improvements could be achieved by taking into account the following issues:

- Due to the limited efficiency of analytical modelling, discrete event simulation remains currently the only way to dynamically describe entire production behaviour.

- Marketing-mix parameters are difficult to estimate, as they are not crisp values. As an example, a product quality may not be set as a precise value. Von Altrock (1995) has included fuzzy logic in business and finance in order to represent subjective judgements. These considerations have lead to a new market characterisation that expresses demand as a fuzzy representation of all marketing-mix variables instead of a pure deterministic or statistical modelling.

- Non-linear system estimation has recently been revitalised using artificial intelligence (such as fuzzy logic, fuzzy neural networks and wavelets identification or prediction), while statistical or Fourier estimations have failed. Results in multiple domains, e.g. automation controlling, have shown a very good prediction and diagnostics behaviour (Leones, 1998). Zuohung Pan and Xiaodi Wang (1998) have introduced an estimator based on the wavelet transform and have shown its remarkable potential for exploring and forecasting non-linear and complex relationships in markets.

This paper intends to incorporate these three new approaches into a new hybrid model that characterises manufacturing and markets mutual influences.

\section{GLOBAL APPROACH}

This part does not intend to explore in detail all techniques but rather presents an overview. Sub-models used in this framework are not detailed in this paper. As 
underlined in the introductory part, the strong correlation between production and market can be modelled as an automation system where critical parameters are mutually transferred. Figure 1 illustrates the split system.

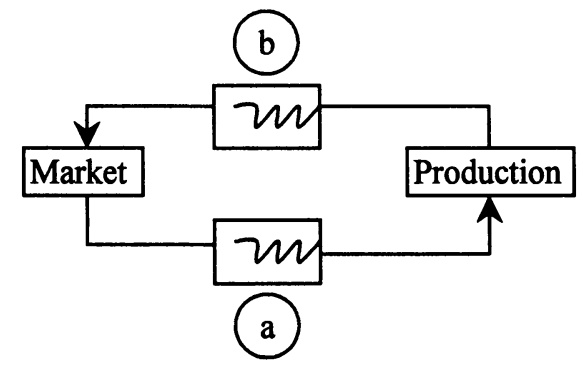

Figure 1 - System rough decomposition

$\mathrm{a}$ and $\mathrm{b}$ denote the parameters transfer. For a specific time horizon, they are set as:

a- $\quad$-Output of 'market': forecast demand time-dependent $\lambda^{*}=\mathrm{f}(\mathrm{t})$, optimal delivery date called 'due-date' and unit tardiness penalty cost provided by market conditions.

-Input of 'production': equals to 'market' output.

b- $\quad$-Output of 'production': lead-times for the entire product-mix, sum of all costs required to produce a certain amount of product-mix, quantities produced.

-Input of 'market': Current delivery delay and market analysis, equals to 'production' output.

Once parameters are quantified, a possible tardiness is determined by subtracting due-date to mean lead-time. The delay quantification is realised by aggregating tardiness into a cost function. This artificial cost may then be added to other traditional costs (e.g. production costs). The aggregation of lateness into a cost parameter is a simple modelling method to evaluate the 'cost of time' in order to define a common scale between time and costs.

Future profit is calculated either including possible tardiness or not. The real profit estimation is $\pi_{1}$ and the profit including lateness is $\pi_{2}$. The difference between $\pi_{1}$ and $\pi_{2}$ quantifies losses due to long delays and emphasises the need to cut down time wasting.

Different sub-models compose the framework as shown in Figure 2. Each specific component will be discussed below. This figure describes the methods used to quantify parameter transfer (as shown in Figure 1). Part a, described in section 3.1, is divided into three domains: temporal analysis of an historical data signal (section 3.1.1) to characterise the system nature, quantification of parameters that determine demand and due-date at a specific date (section 3.1.2) and finally time-dependent demand prevision for the future horizon (section 3.1.3). This reconstructed demand, for a specific time horizon, forecasts future profit if any change occurs within market or production (return on investment, positive or negative demand evolution, delays reductions). Part $b$, depicted in section 3.2, expresses production modelling (section 3.2.1) which provides a sensitivity analysis of a manufacture performance in terms of delays, quantities and costs if the level of demand varies. The cost function including tardiness penalty is decomposed (section 3.2.2 and 3.2.3) to finally calculate the impact of lateness on profit (section 3.3). 


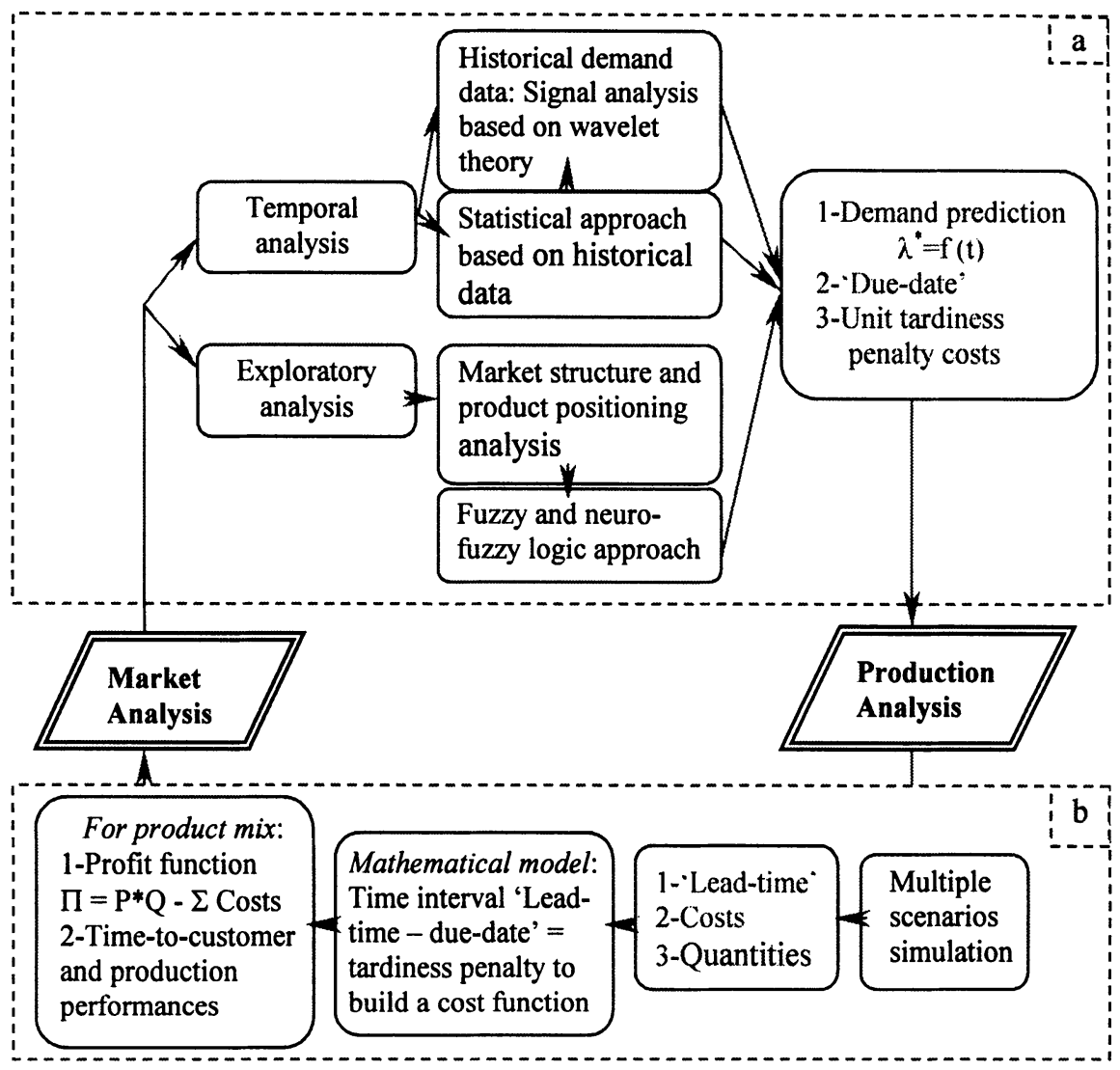

Figure 2 - Model decomposition

\subsection{Market analysis}

The marketing field has been widely explored. Basic terms are referring to classical marketing definitions. Basically, a market is characterised by its structure and a product by its position. Eliasberg et al. (1993) have summed up the existing marketing-mix models: mean demand is linked with other marketing-mix parameters in a semi-linear 'Cobb-Douglas' form. A number of critical parameters have been identified, depending on particular market structures. The basic purpose is to provide a market model, which includes non-linear estimations of historical signals coupled with the influence of marketing-mix parameters at a particular date. The level of demand as a function of time is a two-dimensional representation of a multi-dimensional system. In order to build a reliable prevision of demand, all dimensions are to be taken into account. The level of time-demand is 'tracked' using estimations based on the evolution of multiple parameters.

Assumptions:

a- Level of aggregation: products line of good and no differentiation between customers 
b- $\quad$ Customers are considered as equal regarding due-dates. However, fuzzy logic modelling introduces a differentiation between the perception of parameters.

c- Total demand is a linear combination of each product line of good demand, expressed as: $\left\langle\lambda_{T}\right\rangle=\sum_{i=1}^{N}\left\langle\lambda_{i}\right\rangle$ where $N$ stands for the number of product lines of good involved and $<.>$ is the mean operator. In other words, no cannibalisation is taken into account.

\subsubsection{Historical demand analysis}

The aim of this part is to provide a time-dependent analysis of historical data. Actually, the evolution of demand during a long-term period is supposed to integrate the system dynamic characteristics within a two dimensional representation. This depiction is the most convenient expression to integrate all dimensions as an input parameter of the production simulation. A statistical study is first performed, in order to characterise the maximum likelihood estimate (MLE) corresponding to an existing statistical law. In parallel, regression time-series propose an estimation of historical behaviour. Although these methods have shown their ability in signal diagnostics, the nature of financial data requires a non-linear modelling due to its stochastic variations. Fourier transforms and analysis have a serious drawback, since it cannot preserve the time dependence of the relevant pattern when the series are non-stationary. Wavelet analysis is a quite new and promising set of tools for this purpose. This technique allows a simultaneous transform of time-frequency systems, whereas Fourier loses time considerations. It is subsequently possible to duplicate past evolutions in the future even if mean demand has changed. At first, mother and father wavelets function $\psi$ and $\phi$ are defined in an orthogonal base. Similarly to FFT (Fast Fourier Transform), a fast discrete wavelet transform (FDWT) [Mallat, 1989] extracts wavelet coefficients $\hat{\alpha}_{\mathrm{j}, \mathrm{k}}$ and $\hat{\beta}_{\mathrm{j}, \mathrm{k}}$. These coefficients describe the timespace and time-scale view of the signal and are related to the point where a certain level of demand appears. The wavelet transform vector $\mathrm{W}_{\mathrm{t}}{ }_{\mathrm{T}}^{\mathrm{T}}$ and the wavelet vector $\omega_{t}$ are then set to characterise the demand signal by an analytical function, which is not described in this paper. When the underlying structure of demand is known, it is fairly easy to build a prediction with wavelet estimator.

\subsubsection{Demand evolution for a specified time horizon}

Once the demand signal has been represented as a function of time, a necessary state-space description, called 'exploratory analysis', introduces market structure and product positioning. Actually, once market parameters influencing the level of demand at time $T_{i}$ are identified, any modification can easily be predicted at time $T_{i+1}$ since the underlying structure is known. Classical marketing theory is symbolised by the 4 ' $\mathbf{P}$ '. 'Time-to-customer' does not appear in this pattern, though delays are considered as critical parameters in demand evolution. Therefore, the latest ' $P$ ' has been introduced, namely precision. Figure 3 provides the new marketing-mix 5 'P' system. 

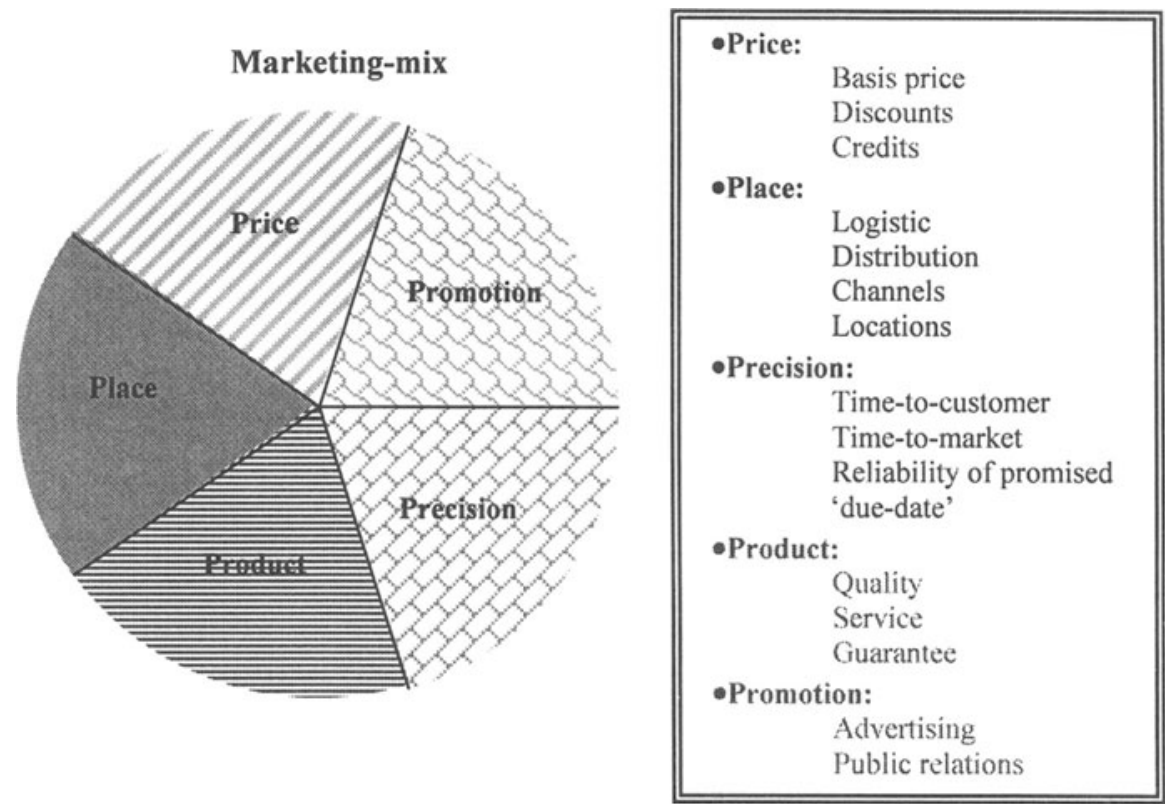

Figure 3 - Marketing-mix 5 'P'

Precision includes both the required due-date and its reliability. A huge number of parameters are involved, which can be reduced by a market analysis. As an example, industrial markets are less influenced by promotion than consumption markets. A particular case is shown in Figure 4. The specific market chosen is the machinerytool market, a sub-set of the industrial markets. Only critical parameters are selected to limit the system size. The best competitors are included so as to a-size the variables. The state-space modelling uses fuzzy logic and fuzzy neural networks techniques. The expanding popularity of fuzzy logic systems is related to its ability to deal with complex systems in a linguistic approach. Since its creation in 1965 by Lofti Zadeh, fuzzy set theory has enjoyed fruitful achievements both in theory and applications. The motivation of this theory is mainly to provide a formal, powerful and quantitative framework to cope with the vagueness of human knowledge as it is expressed by means of natural languages and based on intuitive reasoning, subjectivity and ambiguity. A term like 'quality' cannot be set as a precise value, as it depends on subjective human judgement and is not represented in a universally defined scale (opposite of crisp values). Fuzzy logic systems allow linguistic variables to interfere into a model. The advantages lie in three main points: 1mathematical model is not needed, 2- non-linear and stochastic systems are treated, 3- this method is rapidly computed. Basically, a fuzzy system is made out of two parts: the first one is membership functions set and the second provides fuzzy rules. Membership functions simply transform a linguistic or crisp variable into fuzzy grades. The conventional approach to design is to capture a set of linguistic fuzzy rules given by human experts. Another is the rule learning using neural networks techniques. Training fuzzy systems using a set of input-output data improve their 'intelligence'. With a time partitioning technique (clusterisation) and learning from 
historical data, the fuzzy neural networks system models non-linear non-parametric demand evolution. The fuzzy trained system can be viewed as interpolation procedures between inputs and outputs. The future mean demand prediction is then possible: experts provide future market structure and product position with intuitive knowledge at time $T_{i+1}$. The fuzzy system indicates which demand and acceptable due-date will occur at this time.

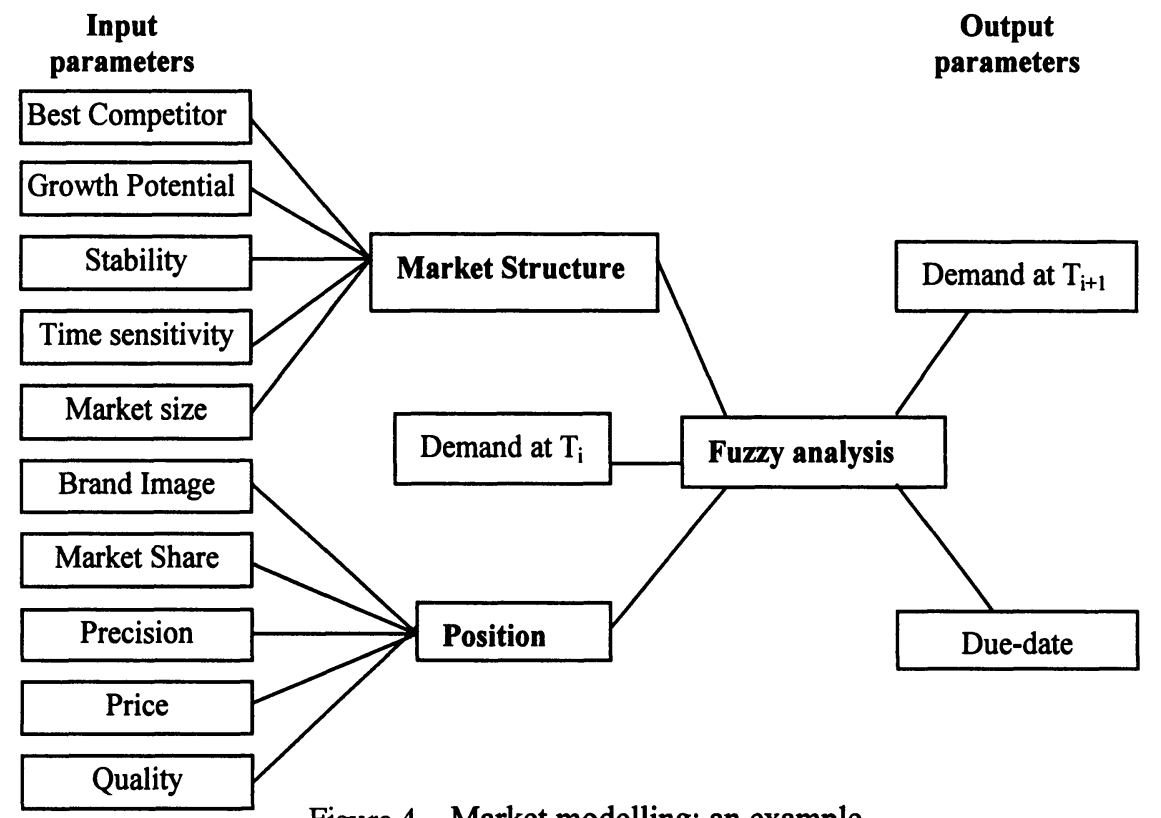

Figure 4-Market modelling: an example

\subsubsection{Signal reconstruction}

The time horizon $\Delta T=T_{i+1}-T_{i}$ is determined by experts knowledge of parameters values at $T_{i+1}$. This period of time varies from short to long-term periods. This statement enforces this new technique use as demand analysis and forecast evolution was not possible in a long-term period using traditional semi-linear models. In this section, signal reconstruction combines fuzzy system and wavelet-based estimators. The fuzzy system provides demand and due-date values at $T_{i}$ and $T_{i+1}$. Let $\mathbf{X}_{t}$ be the input at $T_{i}$ and $Y_{t}$ the output at $T_{i+1}$ which are known values at this step. The signal reconstruction consists in approximating $\mathbf{Y}_{t}=f\left(X_{t}\right)$ on the interval $\Delta T$ with wavelet historical data analysis. The approximation uses the wavelet transform vector $\mathbf{W}_{\mathbf{t}}^{\mathbf{T}}$ and the wavelets vector $\omega_{t}$ previously determined. The approximation function $\widetilde{f}$ is computed in an iterative way until $\mathbf{Y}_{t}$ is reached with a negligible error. It can be shown that $\widetilde{f}=W_{t}^{T} \omega_{t}+\varepsilon_{t}$. where $\varepsilon_{t}$ stands for the error estimation (which has to be as small as possible). The signal is then reconstructed both in state and time-scale estimation. $\widetilde{f}$ represents the demand evolution during the interval $\left[T_{i}, T_{i+1}\right]$. 


\subsection{Production analysis}

A particular manufacturing case determines an information, financial and material flow model along processes.

\subsubsection{Methods}

As discussed previously, a discrete event simulation of the current production system gives a tendency analysis depending on chosen parameters. This type of methods can dynamically model a production system, depending on the desired level of aggregation. Although this technique remains a powerful tool to characterise the global production system, it does not provide an analytical function to link outputs and inputs. Another drawback restraints the use of such a method: each particular case needs to be treated independently as no global methodology exists to include all production systems. However, analytical optimised fits are performed to represent lead-times and costs (outputs) as functions of demand arrivals (inputs) for each specific case. If present performances reveal themselves inadequate, multiple enhancement scenarios (time reduction actions) are created. Enhancements can be a machine or material investment, increased shift flexibility or a new production control system (e.g. Just in time implementation). The $\mathrm{N}$ created scenarios are simulated with current and future demand and due-date as input parameters. Respective performances are compared to keep those increasing efficiency such as lead-time and costs. A major question arises: are returns on investment worthwhile? In other words, is the increase profit sufficient to compensate for the investment? Accordingly, tardiness has to be penalised to balance the investment cost and the lead-time gain.

\subsubsection{Cost model and decomposition}

A cost accounting model is built to aggregate 'time' into a cost function. For each scenario, a rough decomposition of the current production gives the make-to-stock (MTS) and make-to-order (MTO) repartition. The interface between them is considered as an intermediate central inventory. Simulations give lead-time values while demand varies. Market modelling provides an acceptable due-date for several periods, and a future demand (forecast market requirements). Depending on delays and production control repartitions, costs are set either by a traditional cost accounting or by a tardiness penalty cost accounting. This information is summarised in Figure 5.

A Traditional cost accounting ( $\mathrm{ABC}$ method) along the production process, no penalty

B Weak penalty (as demand may decrease)

C Strong tardiness penalty depending on market sensitivity

The global cost function is represented by $C_{T}=C_{A}+C_{B}+C_{C}=C_{A}+C_{B C}$ 


\subsubsection{Tardiness accounting}

Requirements concerning the penalty cost function are: 1- convexity

\section{2- increasing with time}

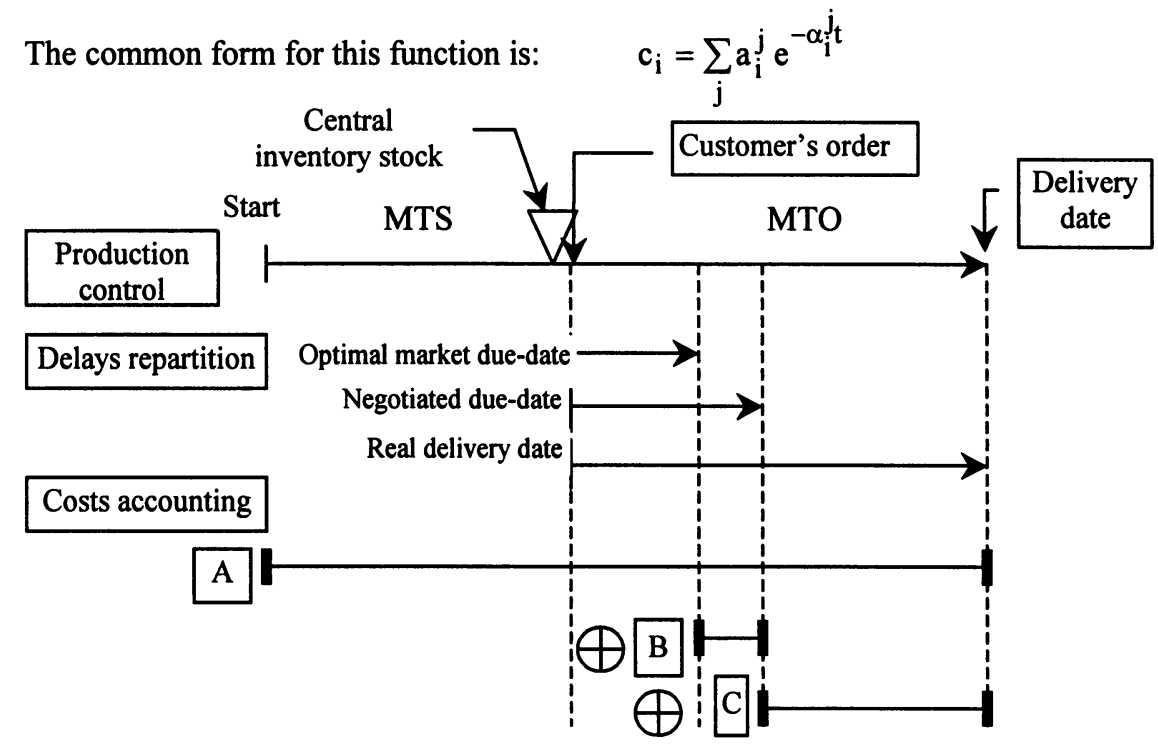

Figure 5 - Model decomposition and cost accounting

$\mathrm{i}$ represents the different zones, $\mathrm{i} \in\{\mathrm{B} ; \mathrm{C}\}$ and $\mathrm{a}_{\mathrm{i}}^{\mathrm{j}}$ are the unit costs. Productions in batch or dedicated lines compose the manufacturing processes. During the MTO phase, no inventory or back-order costs are taken into account. The relevant operational costs include processing costs $(j=1)$, set-up costs $(j=2)$ and queuing costs $(j=3)$. Simulation results have modelled lead-time function of demand arrivals over the interval $\left[\mathrm{T}_{\mathrm{i}}, \mathrm{T}_{\mathrm{i}+1}\right] .\left[0, \mathrm{~L}_{\mathrm{T}}\right]$ is a fraction of this previous interval where tardiness occurs.

The lead-time $L_{T}$ may be split into three parts following costs partition as $L_{T}=$ $T_{\text {processing }}+T_{\text {set-up }}+T_{\text {queuing, }}$, easily computed by simulation. An optimised fit $f$ of simulation results gives: $L_{T}=f(\lambda) \Rightarrow \sum_{j=1}^{3} T_{j}=f_{j}(\lambda)=f_{j}(\tilde{f}(\lambda(t)))$

Where $\lambda=\tilde{f}(\lambda(t))$ is provided by market analysis during the same interval. The penalty cost is then computed as:

$$
\begin{gathered}
C_{B C}=\sum_{i=1}^{2}\left(\int_{0}^{T_{j}}\left(\sum_{j=1}^{3} a_{i}^{j} e^{-\alpha_{i}^{j_{i}} \tau}\right) f_{j}(\lambda(\tau)) d \tau\right) \\
C_{B C}=\sum_{i=1}^{2} \sum_{j=1}^{3}\left(a_{i}^{j}\left(\int_{0}^{T_{j}} e^{-\alpha_{i}^{j} \tau} f_{j}(\lambda(\tau)) d \tau\right)\right)
\end{gathered}
$$


All production control features are included within $T_{j}$ as provided by simulation. $C_{B C}$ is computed depending on $f_{j}$. The expression of this function varies from one production type to another and the general expression is not given here.

\subsubsection{Global cost function}

The global cost function only represents the linear sum of all parts. If any investment occurs, its cost is simply added to the global function. Cost is the most important factor in technology selection. Linear functions continue to be used over a wide range of applications. Luss [1982] pointed out that the fixed charge cost function has been extensively used in the development of analytical models for capacity planning and is still very useful in capturing characteristics exhibited by several production technologies. The acquisition cost function can be expressed as:

$$
C_{n}\left(P_{n}\right)=f_{n}+b_{n} \times P_{n}
$$

Where $P_{n}$ stands for the machine speed, $f_{n}$ the fixed acquisition cost and $b_{n}$ the variable acquisition cost. The global cost function is set as below:

$$
\begin{aligned}
& C_{T}=C_{n}+C_{A}+C_{B C} \\
& C_{T}=f_{n}+b_{n} \times P_{n}+C_{A}+\sum_{i=1}^{2} \sum_{j=1}^{3}\left(a_{i}^{j}\left(\int_{0}^{T_{j}^{j}} e^{-\alpha_{i}^{j} \tau} f_{j}(\lambda(\tau)) d \tau\right)\right)
\end{aligned}
$$

The acquisition of multiple different investments may be compared using $\mathrm{C}_{\mathrm{T}}$. The best one has the smallest $C_{T}$.

\subsection{Profit evaluation}

The evaluation of losses due to poor performances implies the determination of profit variation. The market model provides a level of demand either including tardiness (2) or not (1) (precision is set equal to 1). To calculate $\pi_{1}-\pi_{2,}$ prices are similar and costs do not include tardiness penalty (traditional $\mathrm{ABC}$ accounting). Nevertheless, the difference $\pi_{1}-\pi_{2}$ is proportional to penalty costs $C_{B C}$.

$$
\text { Profit losses }=\pi_{1}-\pi_{2}=\mathrm{k}^{\alpha} \times \mathrm{C}_{\mathrm{BC}}
$$

Market structure fixes the proportional factor $\mathrm{k}^{\alpha}$ (chosen factor). This $\mathrm{k}^{\alpha}$ factor classifies types of markets in term of delay impacts. The smaller $k^{\alpha}$ is, the less sensible to tardiness markets are. A market benchmarking could be useful for managers to estimate their performances.

\section{CONCLUSION}

A global model has been presented, allowing the economic quantification of delays occurring within the supply chain. Traditional production and marketing models are mainly based on analytical formulations, which restrict application fields and the model accuracy. To overcome this difficulty, expert system techniques and discrete event simulation have been introduced. To perform efficient evaluation of delays within market modelling, a new concept, namely 'precision' has been introduced. This particular kind of model uses several techniques to characterise profit decrease 
due to poor performances in term of delayed delivery dates. The new modelling techniques involved and the global approach that reduces the number of undefined parameters constitute the major advantages. Although analytical functions are not imparted, dynamic and non-linear behaviours are represented. This approach constitutes an interesting tool to quantify the efficiency of delay shortening, such as investments in flexible device. A particular case, i.e. return on investment, has been studied to validate the proposed model. Detailed formulations of the sub-models will be published in a further paper.

\section{REFERENCES}

1. Abad PL. "Multi-product Multi-market model for co-ordination of marketing and production decisions". International Journal of Systems Science, Nov. 1989; $20 \mathrm{n}^{\circ} 11$.

2. Alpern S, Snower DJ. "A search model of optimal pricing and production". Engineering Costs and Production Economics, May 1989; 15.

3. Banker RD., Datar, SM, Kekre S. "Relevant costs, congestion and stochasticity in production environments". Journal of Accounting and Economics, 1992; 10.

4. Buss AH, Lawrence SR, Kropp DH. "Volume and capacity interaction in facility design". IIE Transactions, $1994 ; 26 n^{\circ} 4$.

5. Corbey M. "Measurable economic consequences of investments in flexible capacity". International Journal of Production Economics, Oct. 1991; 23 n $1-3$.

6. De P, Dunne EJ, Ghosh JB, Wells CE. "Discrete time-cost trade-off revisited". European Journal of Operational Research, March $1995 ; 81 \mathrm{n}^{\circ} 2$.

7. Eliasberg J, Lilien GL, Gatignon H. "Marketing Mix Models". Handbooks in operational research, 1993; 5.

8. Federgruen A, Tzur, M. "Joint replenishment problem with time-varying costs and demands: efficient, asymptotic and epsilon-optimal solutions”. Operations Research, Dec. 1994; $42 \mathrm{n}^{\circ} 6$.

9. Guiffrida AL, Nagi R. "Fuzzy set theory application in production management research: a literature survey". Journal of Intelligent Manufacturing, Feb. 1998; $9 \mathrm{n}^{\circ} 1$.

10. Hariga M. "Inventory lot-sizing problem with continuous time-varying demand and shortages". Journal of the Operational Research Society, Jul. 1994; $45 \mathrm{n}^{\circ} 7$.

11. Hatoum KW, Chang Y-L. "Trade-off between quoted lead-time and price". Production Planning and Control, Mar. 1997; $8 \mathrm{n}^{\circ} 2$.

12. Heliashberg J, Steinberg R. "Marketing-Production joint decision making". Handbooks in operational research, $1993 ; 4$.

13. Hill A, Khosla I. "Models for optimal lead-time reduction". Production and Operations Management, $1992 ; 1 n^{\circ} 2$.

14. Karmarkar US, Kekre S. "Multi-item batching heuristics for minimisation of queuing delays". European Journal of Operational Research, 1992; 58.

15. Kim D, Lee WJ. "Optimal co-ordination strategies for production and marketing decisions". Operations Research Letters, $1998 ; 22 \mathrm{n}^{\circ} 1$.

16. Kim I, Tang CS. "Lead-time and response time in a pull production control system". European Journal of Operational Research, Sep. 1997; $101 \mathrm{n}^{\circ} 3$.

17. Kingsman B, Worden L, Hendry L, Mercer A, Wilson E. "Integrating marketing and production planning in make-to-order companies". International Journal of Production Economics, Jul. 1993; 30-31.

18. Kingsman B, Hendry L, Wilson E. "Decision support system for the dynamic planning of customer order intake and capacity resources for make-to-order companies". IFIP Transactions B: Computer Applications in Technology, 1993; B-13.

19. Lederer $\mathrm{P}, \mathrm{Li} \mathrm{L}$. "Pricing, production, scheduling and delivery-time competition". Operations Research, 1994; $45 \mathrm{n}^{\circ} 3$.

20. Leones CT. "Fuzzy logic and expert systems applications". Academic Press, 1998; 6.

21. Li L, Lee YS. "Pricing and delivery performance in a competitive environment". Management Science, $1994 ; 40 \mathrm{n}^{\circ} 5$.

22. Li S, Qiu J. "Models for capacity acquisition decisions considering operational costs". International Journal of Flexible Manufacturing Systems, Jul. 1996; $8 \mathrm{n}^{\circ} 3$.

23. Loch, C. "Pricing in markets sensitive to delay". Stanford University, CA 1991. 
24. Madu CN. "Sensitivity of inventory models with demand trend". Computers \& Industrial Engineering, $1990 ; 18 \mathrm{n}^{\circ} 2$.

25. Malhotra NK. "Marketing research". Prentice Hall, 1999.

26. Palaka K., Erlebacher S, Kropp DH. "Lead-time setting, capacity utilisation, and pricing decisions under lead-time dependant demand". IIE transactions (Institute of Industrial Engineers), Feb. 1998; $30 \mathrm{n}^{\circ} 2$.

27. Qiu J, Loulou R. "Multi-product production / inventory control under random demands". IEEE Transactions on Automatic Control, Feb. 1995; $40 \mathrm{n}^{\circ} 2$.

28. Rosling K. "Optimal inventory policies for assembly systems under random demands". Operations Research, Jul-Aug $1989 ; 37 \mathrm{n}^{\circ} 4$.

29. Selladurai V, Aravindan P, Satheesan R. "Development of a computer simulator for dynamic scheduling of FMS to achieve optimal performance". International journal of advanced manufacturing technology, 1996; $12 \mathrm{n}^{\circ} 2$.

30. Senechal O, Tahon C. "Modelling approach for production costing and continuous improvement of manufacturing processes". Production planning and control, Dec 1997; 8 n8.

31. So K.C, Song J-S. "Optimal pricing, lead-time and capacity expansion decisions". University of California, 1994.

32. Spedding TA, Sun GQ. "Application of discrete event simulation to the activity based costing of manufacturing systems". International journal of production economics, Jan 1999; 58 n³.

33. Varian HR. "Micro economic analysis". W. W. Norton Company, 1984.

34. Vendemia, WG, Patuwo BE, Hung MS. "Evaluation of lead-time in production / inventory systems with non-stationary stochastic demand". Journal of the Operational Research Society, Feb. 1995; $46 n^{\circ} 2$.

35. Von Altrock C. "Fuzzy logic and neuro fuzzy applications in business and finance". Prentice Hall, 1995.

36. Zuohong Pan, Xiaodi Wang. "A stochastic non-linear regression estimator using wavelets". Computational economics, 1998; $11 \mathrm{n}^{\circ} 1-2$. 